\title{
Comparative analysis of remifentanil versus dexmedetomidine in the incidence of pain in a post-anesthesia care unit after bariatric surgery
}

\author{
Análise comparativa de remifentanil versus dexmedetomidina na incidência de dor na unidade \\ de recuperação pós-anestésica após cirurgia bariátrica
}

Leopoldo Muniz da Silva1, Saullo Queiroz Silveira1, Arthur de Campos Vieira Abib¹, Wilson Porfírio de Medeiros Nunes ${ }^{1}$, Otto Mittermayer $^{1}$, Daniel Rodrigues de Oliveira ${ }^{1}$

DOI 10.5935/2595-0118.20180043

\section{ABSTRACT}

BACKGROUND AND OBJECTIVES: Compare anesthesia techniques with sufentanil and intraoperative infusion of remifentanil or dexmedetomidine, and to then analyze their associations with the incidence of pain and other complications in the post-anesthesia care unit.

METHODS: A retrospective analytical observational study conducted in a reference center for bariatric surgery in Sáo Paulo, São Paulo State, Brazil. Patients $(n=120)$ included in the study were randomly selected using this site's anesthesia records for bariatric surgery. Four 30-patient groups were established: G1 - induction with $0.5 \mu \mathrm{g} \cdot \mathrm{kg}^{-1}$ sufentanil associated with the continuous infusion of remifentanil; G2 - induction with $0.7 \mu \mathrm{g} \cdot \mathrm{kg}^{-1}$ sufentanil associated with the continuous infusion of remifentanil; G3 - induction with $0.5 \mu \mathrm{g} \cdot \mathrm{kg}^{-1}$ sufentanil associated with the continuous infusion of dexmedetomidine; and G4 - induction with $0.7 \mu \mathrm{g} \cdot \mathrm{kg}^{-1}$ sufentanil associated with the continuous infusion of dexmedetomidine. Significance was set at $\mathrm{p}<0.05$.

RESULTS: The incidence of pain in the post-anesthesia care unit was $52.5 \%$ ( $n=63$ ). It was considered intense in $36.11 \%$ of these cases. The incidence of pain in the post-anesthesia care unit was lower in patients receiving a continuous infusion of dexmedetomidine relative to those who received remifentanil infusion. Sufentanil dosage in anesthesia induction did not influence the incidence of pain $(\mathrm{G} 1=\mathrm{G} 2>\mathrm{G} 3=\mathrm{G} 4 ; \mathrm{p}<0.05)$. The occurrence of respiratory complications did not differ significantly between the groups.

CONCLUSION: The use of dexmedetomidine proved to be better for analgesia in the post-anesthesia care unit, and it did not increase the risk of respiratory complications when compared to the continuous infusion of remifentanil, regardless of the sufentanil dose used for induction.

Keywords: Anesthesia, Bariatric surgery, Complications, Pain, Safety.

1. Hospital Sấo Luiz, Rede D’or, Departamento de Anestesiologia, Sấo Paulo, SP, Brasil.

Submitted in March 07, 2018.

Accepted for publication on June 28, 2018.

Conflict of interests: none - Sponsoring sources: none.

Correspondence to

Rua Dr. Alceu de Campos Rodrigues, 229, Conj. 403 - Itaim Bibi

04544-000 São Paulo, SP, Brasil.

E-mail: leopoldo_muniz@hotmail.com

(C) Sociedade Brasileira para o Estudo da Dor

\section{RESUMO}

JUSTIFICATIVA E OBJETIVOS: O objetivo deste estudo foi comparar técnicas anestésicas com sufentanil em diferentes doses na indução anestésica e infusão contínua de remifentanil ou dexmedetomidina no intraoperatório para manutenção da anestesia, relacionando tais fatores à incidência de dor, náuseas e vômitos no pós-operatório e demais complicações na sala de recuperação pós-anestésica.

MÉTODOS: Estudo observacional analítico retrospectivo realizado em pacientes obesos $(\mathrm{n}=120)$. Os pacientes incluídos foram selecionados aleatoriamente e constituíram 4 grupos de 30 pacientes cada: G1 - indução com sufentanil $0,5 \mu \mathrm{g} \cdot \mathrm{kg}^{-1}$ associado à infusão continua de remifentanil; G2 - indução com sufentanil $0,7 \mu \mathrm{g} \cdot \mathrm{kg}^{-1}$ associado à infusão contínua de remifentanil; G3 indução com sufentanil $0,5 \mu \mathrm{g} \cdot \mathrm{kg}^{-1}$ associado à infusão contínua de dexmedetomidina; G4 - indução com sufentanil $0,7 \mu \mathrm{g} \cdot \mathrm{kg}^{-1}$ associado à infusão contínua de dexmedetomidina. Considerou-se como critério de significância valor de $\mathrm{p}<0,05$.

RESULTADOS: A incidência de dor na sala de recuperação pós-anestésica foi de 52,5\% (n=63) e, entre esses, em 36,11\% dos casos foi considerada intensa. A incidência de dor foi menor nos pacientes que receberam infusão de dexmedetomidina comparado àqueles que receberam infusão de remifentanil. A dose de sufentanil na indução anestésica não influenciou na incidência de dor $(\mathrm{G} 1=\mathrm{G} 2>\mathrm{G} 3=\mathrm{G} 4)(\mathrm{p}<0,05)$. A ocorrência de complicaçóes respiratórias não apresentou diferença estatisticamente significativa entre os grupos.

CONCLUSÃO: O uso de dexmedetomidina apresentou vantagem em relação à analgesia na sala de recuperação pós-anestésica, sem aumento no risco de complicaçóes respiratórias, quando comparado à infusão contínua de remifentanil, independentemente da dose de sulfentanil utilizada na indução.

Descritores: Anestesia, Cirurgia bariátrica, Complicaçôes, Dor, Segurança.

\section{INTRODUCTION}

In obese patients, adequate postoperative analgesia aims to provide comfort, early mobilization, and improved respiratory function. Anesthesia in obese patients requires special care and knowledge of the physiological alterations and their repercussions on the pharmacokinetics and pharmacodynamics of anesthetics. 
Postoperative pain, nausea, and vomiting are relevant events since they lead to discomfort and contribute to greater morbidity ${ }^{1-3}$. In the post-anesthesia care unit (PACU), managing postoperative pain is essential for the respiratory system to be able to adapt after the deflation of the pneumoperitoneum, as well as for more comfortable, safer, and earlier patient recovery. The choice of anesthesia technique and the types of drugs used may be important for better managing postoperative pain. Administering sufentanil as the anesthesia induction opioid in morbidly obese patients has not been associated with respiratory complications, decreased oxygen saturation in pulse oximetry, or postoperative nausea and vomiting (PONV) in the PACU, and it has been found to reduce the incidence of pain when compared with other opioids used in general anesthesia ${ }^{4}$.

Dexmedetomidine is an innovative drug regarding sedation and analgesia. Its main qualities are faster onset and the ability to allow for rapid titration, enabling the variation in the depth of analgesia and sedation. In addition, it is synergistic with other commonly used anesthetics and exhibits a low incidence of side effects and minimal respiratory depression. Anesthesia with dexmedetomidine is indicated for patients with morbid obesity because it decreases the consumption of anesthetics, contributes to cardiovascular stability, and decreases the incidence of pain, thus promoting early postoperative recovery ${ }^{5}$. However, the difference between the continuous infusion of dexmedetomidine and the infusion of remifentanil intraoperatively and its relationship with the incidence of pain and respiratory complications in the PACU has yet to be assessed.

Thus, the objectives of this study were to compare anesthesia techniques with sufentanil at different doses at anesthesia induction and continuous intraoperative infusion of remifentanil or dexmedetomidine for maintenance of anesthesia, and to then analyze their associations with the incidence of pain, PONV, and other complications in the PACU.

\section{METHODS}

A retrospective analytical observational study was conducted by the Anesthesiology Department of São Luiz Hospital, in São Paulo, Brazil, a reference center for obesity surgery.

The patients included in this study $(\mathrm{n}=120)$ were randomly selected using the above mentioned department's anesthesia records on video-laparoscopic bariatric surgery, in which data on the anesthesia technique and pharmaceuticals used were recorded. The cases were analyzed using medical charts identified only by their numbers. Information on anesthesia techniques was obtained from the anesthesia chart in order to form the groups, while the outcomes involving pain, nausea, vomiting, and complications in the PACU were obtained from the PACU patient records. Case numbers were randomly selected from the surgeries performed between October 2016 and May 2017. The cases were divided into 4 groups according to anesthesia technique reported. Each group had 30 randomly selected patients, for a total sample of 120 patients.

\section{Standard institutional anesthesia protocol}

All patients were assessed in a preanesthesia consultation, when data on their weight $(\mathrm{kg})$ and height $(\mathrm{cm})$ were collected to estimate the body mass index (BMI) $\left(\mathrm{kg} / \mathrm{m}^{2}\right)$.
The anesthesia technique adopted and included in the study was general balanced anesthesia with sevoflurane in a concentration sufficient to maintain the bispectral index (BIS) between 40 and 60. The minimum alveolar concentration (MAC) for sevoflurane required was $1.5 \%$. As part of a previously established routine of the anesthesiology department, the patients were administered $40 \mathrm{mg}$ parecoxib, $40 \mathrm{mg}$ pantoprazole, and dexamethasone at a dose of $0.1 \mathrm{mg} \cdot \mathrm{kg}^{-1}$ of adjusted body weight (ABW) up to a maximum of $10 \mathrm{mg}$, intravenously.

In the operating room, monitoring consisted of electrocardioscope, pulse oximeter, automated non-invasive blood pressure measurement with an appropriate cuff covering $75 \%$ to $100 \%$ of the arm, and capnograph with a gas analyzer and BIS values. Patients were in a supine position on the operating table with a discreet 10-degree head elevation. All patients received mechanical prophylaxis for venous thromboembolism during surgery and pharmacological prophylaxis postoperatively. After peripheral puncture and preoxygenation with $100 \%$ oxygen, anesthetic induction was conducted. Controlled ventilation was performed in a closed loop with a flow rate of up to $2 \mathrm{~L} \cdot \mathrm{min}^{-1}$, tidal volume of up to $8 \mathrm{~mL} \cdot \mathrm{kg}^{-1} \mathrm{ABW}$, up to $50 \% \mathrm{FiO}_{2}$, and a respiratory rate sufficient to maintain the expired $\mathrm{CO}_{2}$ fraction between 35 and $40 \mathrm{mmHg}$.

\section{Study groups}

The entire healthcare routine was identical for all patients in the four groups since it followed a previously established protocol. Monitoring and anesthesia techniques were also the same except for the continuous infusion of dexmedetomidine or remifentanil to keep the patient under anesthesia, which varied according to the doses of sufentanil used in anesthesia induction.

Induction initiated with oxygenation with a face mask, followed by intravenous induction with the sequential administration of the following drugs: 0.5 or $0.7 \mu \mathrm{g} . \mathrm{kg}^{-1}$ (actual weight) sufentanil, propofol (2 to $\left.3 \mathrm{mg} \cdot \mathrm{kg}^{-1}\right)$, and rocuronium (1 mg/kg of ideal weight). Both doses of sufentanil were included in the institutional protocol, and the choice was made by the anesthesiologist and then duly registered in the anesthesia chart. All patients were monitored with a TOF watch in order to keep a post-tetanic count under 5 (deep neuromuscular block). Blocker follow-up administration was gauged according to TOF results. Additional doses corresponded to $15 \%$ of the initial dose until reached deep block. Neuromuscular block was reverted with sugammadex for all patients according to TOF results. The study groups for comparison were as follows:

- Group 1 - induction with $0.5 \mu \mathrm{g} \cdot \mathrm{kg}^{-1}$ (actual weight) sufentanil and continuous infusion of remifentanil hydrochloride at doses sufficient to maintain adequate anesthesia and individualized for each case ( 0.1 to $0.3 \mu \mathrm{g} . \mathrm{kg}$. $\left.\mathrm{min}^{-1}\right)$ without the use of boluses of other opioids;

- Group 2 - induction with $0.7 \mu \mathrm{g} \cdot \mathrm{kg}^{-1}$ (actual weight) sufentanil and continuous infusion of remifentanil hydrochloride at doses sufficient to maintain adequate anesthesia and customized for each patient ( 0.1 to $\left.0.3 \mu \mathrm{g} . \mathrm{kg} \cdot \mathrm{min}^{-1}\right)$ without the use of boluses of other opioids;

- Group 3 - induction with $0.5 \mu \mathrm{g} \cdot \mathrm{kg}^{-1}$ (actual weight) sufentanil and continuous infusion of dexmedetomidine: initial bolus of 
$1 \mu \mathrm{g} \cdot \mathrm{kg}^{-1}$ administered over $10 \mathrm{~min}$, followed by maintenance of 0.4 to $0.7 \mu \mathrm{g} \cdot \mathrm{kg}^{-1} \cdot \mathrm{h}^{-1}$ based on adjusted body weight;

- Group 4 - induction with $0.7 \mu g \cdot \mathrm{kg}^{-1}$ (actual weight) sufentanil and continuous infusion of dexmedetomidine: initial bolus of $1 \mu \mathrm{g} \cdot \mathrm{kg}^{-1}$ administered over $10 \mathrm{~min}$, followed by maintenance of 0.4 to $0.7 \mu \mathrm{g} \cdot \mathrm{kg}^{-1} \cdot \mathrm{h}^{-1}$ based on adjusted body weight.

The continuous infusion of both solutions was turned off 10 minutes before the end of the pneumoperitoneum.

Adjusted body weight was estimated with the following formula: ideal weight plus ( $0.4 \mathrm{x}$ overweight). Ideal weight was estimated using height $(\mathrm{m})\left(\mathrm{m}^{2}\right)$ subtracted from 100 for men or 105 for women. The variables studied were age, sex, weight, height, BMI, heart rate (HR), non-invasive blood pressure (NIBP), oxygen saturation $\left(\mathrm{SO}_{2}\right)$, axillar temperature $\left({ }^{\circ} \mathrm{C}\right), \mathrm{P}_{\mathrm{ET}} \mathrm{CO}_{2}$ values by capnography, anesthesia time (time between anesthesia induction and extubation in min), awakening time (time between the end of surgery and extubation in min) and postoperative complications (pain, PONV, and respiratory repercussions in the PACU). Data regarding the variables $\mathrm{HR}$, NIBP, $\mathrm{P}_{\mathrm{ET}} \mathrm{CO}_{2}$, temperature, and $\mathrm{SpO}_{2}$ were examined before starting the induction, and every 10 min until the end of the anesthesia procedure.

Near the end of the procedure ( 20 minutes prior), all patients received dipyrone $2000 \mathrm{mg}$, ondansetron hydrochloride dihydrate at a dose of $0.1 \mathrm{mg} \cdot \mathrm{kg}^{-1}$ of ABW up to the dose of $8 \mathrm{mg}$, and morphine at a dose of $100 \mu \mathrm{g} . \mathrm{kg}^{-1}$ of ABW, intravenously. Before the anesthesia induction, previous hydration was conducted with $10 \mathrm{~mL} \cdot \mathrm{kg}^{-1}$ Ringer's lactate solution for all patients. Intraoperatively, the infusion of liquids was $5.0 \mathrm{~mL} \cdot \mathrm{kg}^{-1} \cdot \mathrm{h}^{-1}$.

\section{Post-anesthesia recovery}

In the PACU, all patients were monitored with an electrocardioscope, pulse oximeter, thermometer and automated non-invasive blood pressure measurement. Patients in the PACU were assessed at four different 15-minute intervals: M1 - PACU admission; M2 - 15 min after admission; M3 - 30 min after admission; and M4 - 45 min after admission. At all intervals, patients were assessed regarding the occurrence of pain and its intensity (using a 0-10 numeric rating scale) as well as PONV and its intensity (1-4 scale). $\mathrm{O}_{2}, \mathrm{HR}$, and NIBP were also assessed by the medical and nursing team at all intervals. Numeric Rating Scale (NRS), 11 points (zero to 10), with point zero representing no pain and point ten (10) the worst possible pain. The remaining numbers represent intermediate intensities of pain (1, 2, 3 and $4=$ mild (25); 5 and $6=$ moderate; 7,8 and $9=$ strong. Sedation scales have not been evaluated. Upon admission to the PACU, patients were assessed to determine their need for supplemental oxygen. M1 comprises the assessment of pulse oximetry without supplemental oxygen. All patients presenting pulse oximetry results of less than $94 \%$ received supplemental oxygen through a face mask with oxygen flow $(5 \mathrm{~L} / \mathrm{min})$. The rescue morphine dose in case of pain in the PACU was 30-50 $\mu \mathrm{g} . \mathrm{kg}^{-1}$ according to the assessment by the PACU anesthesiologist assistant. For patients presenting PONV in the PACU, dimenhydrinate $30 \mathrm{mg}$ was used as a supplementary drug. All patients were classified as high risk for venous thromboembolism and received chemoprophylaxis medications in the postoperative period and antithrombotic device during the surgery. Aldrete-Kroulik index was measured on admission and at discharge from PACU.

\section{Exclusion criteria}

This study did not include chronic opioid users, reoperations, patients allergic to any of the analgesics/anesthetics analyzed, drug users, surgery combined with other surgical procedures, total intravenous anesthesia, anesthesia combined with neuraxial blockades, and patients anesthetized with adjuvant postoperative analgesia medications not included in the standard institutional protocol. All patients included whose charts were not completely or clearly filled out were replaced by the following patient (based on case number).

This study was approved by the Research Ethics Committee (CEP - 72405417.7.0000.0087/2017) and is in compliance with the Declaration of Helsinki.

\section{Statistical Analysis}

Statistical analysis was performed with the Stata/SE software for Windows, version 9.0 (Stata Corp., College Station, Texas, USA). The sample ( $\mathrm{n}=120 / 4$ groups) was estimated to detect a difference of at least $15 \%$ in the incidence of pain among the groups studied considering a test power of $80 \%$, alpha $0.05 \%$. The binomial test for two proportions was used to calculate the study size based on Silva et al. ${ }^{3}$. Categorical variables were presented as absolute values and percentages, while numeric variables were represented as average and standard deviation or median and 25$75^{\text {th }}$ percentiles, as indicated. Histograms and the Shapiro-Wilk test were used to analyze the symmetry of the distribution of the data. Comparisons between groups' pain scores and scales were made using the nonparametric Kruskal-Wallis test, followed by Dunn's post-test if the $p$-value $<0.05$. The Chi-square test was used for categorical variables, and Chi-square partitioning was adopted when the p-value was less than 0.05 . Significance was set at $\mathrm{p}<0.05$, with a $95 \%$ confidence interval.

\section{RESULTS}

Patients in the study had a mean age of $31.18 \pm 11.15$ years. The mean BMI was $41.26 \pm 9.19 \mathrm{~kg} / \mathrm{m}^{2}$. Of all cases, $72.5 \%$ were female. The average anesthesia time was $76.92 \pm 31.36 \mathrm{~min}$, and the average time between the end of surgery and extubation was $15.18 \pm 8.26 \mathrm{~min}$. Most patients underwent gastric bypass $(86.67 \%)$, while the others underwent gastric sleeve surgery. No statistically significant difference between the groups was found in relation to weight $(\mathrm{kg})$, age (years), BMI $\left(\mathrm{kg} / \mathrm{m}^{2}\right)$, temperature $\left({ }^{\circ} \mathrm{C}\right)$ surgery time $(\mathrm{min})$, or surgical technique used $(\mathrm{p}>0.05)$. Intraoperatively, no statistically significant difference between the groups was observed in relation to heart rate, systolic blood pressure, diastolic blood pressure, or $\mathrm{P}_{\mathrm{ET}} \mathrm{CO}_{2}$ values as determined by capnography ( $>0.05)$. Median awakening time (period between end of surgery and extubation) was 15 (10-20) min; in G1 it was $10(10-15) \mathrm{min}$, in G2 it was $10(15-20) \mathrm{min}$, in G3 it was 15 $(10-16) \mathrm{min}$, and in G4 it was $17.5(14.25-27.5) \mathrm{min}$. There was no statistically significant difference between the groups, and G4>G1 $(\mathrm{p}<0.05)$. 
The incidence of pain on the PACU was 52.5\% ( $\mathrm{n}=63)$, and $36.11 \%$ of the patients who reported pain exhibited severe pain (defined as an 8 to 10 score on the numeric rating scale). The groups showed a statistically significant difference in relation to the incidence of pain in the PACU, which was lower among patients receiving a continuous infusion of dexmedetomidine (G3=43.33\%; G4=33.33\%) relative to those receiving remifentanil infusion ( $\mathrm{G} 1=70 \%$; $\mathrm{G} 2=63.33 \%)(\mathrm{p}<0.05)$. Sufentanil dosage in anesthesia induction did not influence the incidence of pain $(\mathrm{G} 1=\mathrm{G} 2>\mathrm{G} 3=\mathrm{G} 4)$. The incidence of PONV was $31.93 \%$, and symptoms were intense in $15 \%$ of these cases. No statistically significant difference was found between the study groups regarding the occurrence of PONV ( $>>0.05)$ (Table 1). For patients presenting pain and PONV in the PACU, there was no statistically significant difference in relation to intensity scores between the study groups $(\mathrm{p}>0.05)$ (Table 2). Other possible factors were considered as possibly being associated with the occurrence of pain in the PACU apart from anesthesia technique, but no statistically significant association was observed with gender $(\mathrm{p}=0.34)$, age (years) $(\mathrm{p}=0.34)$, surgical technique $(\mathrm{p}=0.10)$, or surgery time $(\mathrm{p}=0.70)$.

The occurrence of oxygen saturation less than $90 \%$ as determined by pulse oximetry upon admission to the PACU and without supplemental oxygen occurred in 57\% of the cases. Oxygen saturation between $85 \%$ and $90 \%$ with supplemental oxygen during the period in the PACU occurred in $28.33 \%$ of the cases. None of the cases had a recorded saturation less than $85 \%$ with supplemental oxygen or a need for positive pressure ventilation or reintubation due to hypoxia. Discharge from the $\mathrm{PACU}$ in a period greater than 90 minutes due to pain, PONV, or drowsiness occurred in $16.67 \%$ of the cases. No statistically significant difference between the study groups was found in relation to the occurrence of respiratory complications (Table 3). The frequency of delayed discharge from the PACU exceeding 90 minutes did not differ between the groups $(\mathrm{p}>0.05)$.

Table 1. Comparison between the groups regarding the incidence of pain in the post-anesthesia care unit after anesthesia for bariatric surgery

\begin{tabular}{|c|c|c|c|c|c|}
\hline \multirow[b]{2}{*}{ PACU Outcome } & \multicolumn{4}{|c|}{ Groups } & \multirow[b]{2}{*}{$p$-value* } \\
\hline & G1 & G2 & G3 & G4 & \\
\hline Occurrence of Pain & & & & & 0.01 \\
\hline Yes & $70(21)$ & 63.33(19) & $43.33(13)^{\#}$ & $33.33(10)$ & \\
\hline Pain intensity & & & & & 0.03 \\
\hline Occurrence of PONV & & & & & 0.88 \\
\hline No & $66.67(20)$ & $70.00(21)$ & 63.33(19) & $70.00(21)$ & \\
\hline Yes & $33.33(10)$ & $30.00(9)$ & $36.67(11)$ & $30.00(9)$ & \\
\hline
\end{tabular}

Table 2. Comparison between the groups in relation to the intensity of pain in the post-anesthesia care unit (numerical scale) and scale of postoperative nausea and vomiting symptom intensity after anesthesia for bariatric surgery

\begin{tabular}{lccccc}
\hline & \multicolumn{3}{c}{ Groups } & & \\
Scales & G1 & G2 & G3 & p-value* \\
\hline Pain (1-10) & $6.5(6-7.75)$ & $6(5-7)$ & $7(5.5-8)$ & $6(5-7)$ & 0.45 \\
PONV (1-4) & $2(1-3)$ & $3(1-4)$ & $2(1-2)$ & $2(1-3)$ & 0.84 \\
\hline
\end{tabular}

Values expressed as medians (25-75 th percentiles). ${ }^{*}$ Kruskal-Wallis analysis of variance: G1=G2=G3=G4. G1 = induction with $0.5 \mu$ g.kg ${ }^{-1}$ sufentanil associated with the continuous infusion of remifentanil; G2 = induction with $0.7 \mu \mathrm{g} \cdot \mathrm{kg}^{-1}$ sufentanil associated with the continuous infusion of remifentanil; G3 = induction with 0.5 $\mu \mathrm{g} \cdot \mathrm{kg}^{-1}$ sufentanil associated with the continuous infusion of dexmedetomidine; G4 = induction with $0.7 \mu \mathrm{g} \mathrm{kg}^{-1}$ sufentanil associated with the continuous infusion of dexmedetomidine. $\mathrm{PACU}=$ post-anesthesia care unit; PONV = postoperative nausea and vomiting.

Table 3. Comparison between the groups in relation to respiratory complications and delayed discharge from the post-anesthesia care unit after anesthesia for bariatric surgery

\begin{tabular}{|c|c|c|c|c|c|}
\hline \multirow[b]{2}{*}{ PACU outcome } & \multicolumn{4}{|c|}{ Groups } & \multirow[b]{2}{*}{ p-value* } \\
\hline & G1 & G2 & G3 & G4 & \\
\hline $\mathrm{SO}_{2}$ less than $94 \%$ upon admission and without supplementary $\mathrm{O}_{2}$ & $33.33(10)$ & $40(12)$ & $60(18)$ & $56.67(17)$ & 0.11 \\
\hline $\mathrm{SO}_{2}$ between $85-90 \%$ in the PACU with supplemental $\mathrm{O}_{2}$ & 20(6) & $36.67(11)$ & $26.67(8)$ & $30(9)$ & 0.54 \\
\hline Discharge from the PACU after more than 90 minutes & $23.33(7)$ & $10(3)$ & $13.33(4)$ & 20(6) & 0.49 \\
\hline
\end{tabular}

Values expressed in \% (n). ${ }^{*}$ Chi-square test. G1 = induction with $0.5 \mu \mathrm{g} \cdot \mathrm{kg}^{-1}$ sufentanil associated with the continuous infusion of remifentanil; G2 = induction with 0.7 $\mu \mathrm{g} \cdot \mathrm{kg}^{-1}$ sufentanil associated with the continuous infusion of remifentanil; G3 = induction with $0.5 \mu \mathrm{g} \cdot \mathrm{kg}^{-1}$ sufentanil associated with the continuous infusion of dexmedetomidine; G4 = induction with $0.7 \mu \mathrm{g} \cdot \mathrm{kg}^{-1}$ sufentanil associated with the continuous infusion of dexmedetomidine. $\mathrm{G} 1=\mathrm{G} 2=\mathrm{G} 3=\mathrm{G} 4$. PACU = post-anesthesia care unit. 


\section{DISCUSSION}

The incidence of postoperative pain following bariatric surgery in patients undergoing general anesthesia is a factor to be considered in the choice of anesthetics to be used intraoperatively. This study assessed the institution's standard anesthesia technique and evaluated whether using dexmedetomidine as an adjuvant would benefit morbidly obese patients intraoperatively as well as postoperatively in terms of the most prevalent complications in the PACU. In this study, the continuous infusion of dexmedetomidine intraoperatively contributed to a reduced incidence of pain in the PACU, without any repercussions involving respiratory complications.

Developing an anesthesia and analgesia protocol in bariatric surgery is challenging due to the particular aspects of pain treatment in obese patients ${ }^{3}$. The polymorphism of the gene involved in the pharmacokinetics and pharmacodynamics of opioids may be a factor to justify an individualized antalgic therapy and to explain the different pain scores in obese patients receiving the same analgesic therapy. One study ${ }^{6}$ has identified 3 types of polymorphisms in the mu opioid receptor, with no difference between genders. Associating drugs with other mechanisms of action and analgesic potential guarantees multimodal and more effective analgesia with better outcomes in the recovery, as observed with the use of dexmedetomidine. However, there was still a high incidence of pain, regardless of the anesthetic technique. A systematic and effective assessment in the PACU is essential due to the existence of this individualized response to anesthetics,. This allows for the early identification of patients who are more sensitive to pain and avoids an overdose of analgesics in those with a more effective response to the use of opioids.

The spinal cord has been suggested as the likely main site of analgesic action of $\alpha_{-}{ }_{2}$ adrenergic agonists such as dexmedetomidine. These drugs seem to have analgesic effects on the spinal cord and supraspinal areas. Dexmedetomidine can also provide antinociception through non-spinal mechanisms ${ }^{7}$. Thus, anesthesia with dexmedetomidine provides analgesia in places other than those reached by opioids alone and is, therefore, a potential adjuvant for analgesic control.

Dexmedetomidine has been used in general anesthesia to reduce the use of opioids and thus reduce the incidence of respiratory depression. One surgical center performed more than 2,000 bariatric procedures using a perioperative infusion of dexmedetomidine. This drug was found to be cardioprotective and neuroprotective, presented good hemodynamic stability, and reduced the need for opioids and volatile agents. When compared to fentanyl, dexmedetomidine seemed to offer better postoperative analgesia and mitigated changes in blood pressure?

In two groups of adolescent patients undergoing general anesthesia for bariatric surgery (with and without an infusion of dexmedetomidine as an adjunct to the intraoperative anesthesia technique), pain scores were significantly lower in the group that received dexmedetomidine. The analgesic effects influenced the pain scores on the first postoperative day and reduced the need for rescue opioids in this period ${ }^{10}$. A published meta-analysis on the effects of dexmedetomidine on the perioperative period in obese patients showed a reduction in the need for postoperative analgesics and found it to be a safe and effective adjunct in obese patients ${ }^{11}$. In spite of a reduction in the incidence of PONV with the use of dexmedetomidine determined in the meta-analysis, this effect was not observed in our study.

Remifentanil in continuous infusion is routinely used in anesthesia for obese patients due to its short duration of action and good hemodynamic stability. Its pharmacokinetics does not seem to change in obese patients; therefore, to avoid excess, doses should be estimated based on ideal body weight ${ }^{12}$. In a study comparing intraoperative remifentanil and dexmedetomidine, the dexmedetomidine group exhibited a greater need for rescue analgesia in the first $24 \mathrm{~h}$, a finding which differs from our results. However, the methodology was also different, and patients received epidural for analgesia, which influenced the need for rescue analgesia. The study ${ }^{12}$ also observed that the continuous intravenous administration of remifentanil offered 8 to 10 minutes of advantage over the infusion of dexmedetomidine at the moments of eye-opening, resumption of spontaneous breathing, and orotracheal extubation in morbidly obese patients under a standardized anesthetic technique. This reduction in awakening time was observed in our study, with a longer awakening time in patients undergoing anesthesia with dexmedetomidine and sufentanil at a dose of $0.7 \mu \mathrm{g} \cdot \mathrm{kg}^{-1}$. Nevertheless, this advantage shows no clinical relevance.

Postoperative hypoxia is one of the major complications of surgical interventions in patients with morbid obesity. Dexmedetomidine can be used safely in patients with a high risk of complications. Studies in animals have shown that it not only reduces the need for anesthetics but also has an intrinsic anesthetic property; it is therefore indicated for intraoperative maintenance of anesthesia ${ }^{13,14}$. The current study found a low incidence of respiratory complications, and no hypoxia-related events with a need for positive pressure ventilation were observed. This low incidence can be explained by the ability of the teams to perform the surgery in a reference center and with a shorter surgery time, which leads to lower rates of morbidity. In this case series, surgery time was predominantly limited to 75 minutes, a variable which was not found to be associated with postoperative pain in the PACU. In bariatric surgery, deep relaxation has advantages for surgeon and patient. Compared to the moderate neuromuscular blockade, deep neuromuscular blockade produced stable and improved surgical conditions with less postoperative pain ${ }^{15}$. Deep neuromuscular blockade was used in all patients, and this may be a factor that contributed equally among groups to reduce pain score in the PACU. However, intraabdominal pressure (pneumoperitoneum) was maintained in $15 \mathrm{mmHg}$, which limited the result of the deep neuromuscular blockade to decrease the incidence of pain ${ }^{15}$.

Although a previous study ${ }^{16}$ found reduced recovery times in the PACU, the current study groups exhibited no differences when delayed discharge from the PACU and recovery time longer than 90 minutes were considered. Dexmedetomidine did not delay patient discharge since its sedative potential is greater than that of remifentanil.

One of the limitations of this study is that it did not assess inhalational anesthetic consumption or the reduction in its use 
when associated with dexmedetomidine. Analgesic medication quantities and rescue doses in the PACU were also not assessed, as only the first pain score reported by patients in the PACU was considered as an outcome.

\section{CONCLUSION}

The use of dexmedetomidine in anesthesia maintenance was compared to that of remifentanil. Regardless of the dose of sufentanil used in induction, dexmedetomidine exhibited an advantage to pain management in the PACU, which, in turn, reflected positively on postoperative progress. In addition, dexmedetomidine proved to be safe in terms of intraoperative cardiovascular stability and complications, and for respiratory complications in particular, in the PACU.

\section{REFERENCES}

1. Nguyen NT, Wolfe BM. The physiologic effects of pneumoperitoneum in the morbidly obese. Ann Surg. 2005;241(2):219-26.

2. Schumann R. Anaesthesia for bariatric surgery. Best Pract Res Clin Anaesthesiol. 2011;25(1):83-93.

3. Navarro Martínez MJ, Pindado Martínez ML, Paz Martín D, Caro Cascante M, Mariscal Flores M, Ruiz de Adana JC. [Perioperative anesthetic management of 300 morbidly obese patients undergoing laparoscopic bariatric surgery and a brief review of relevant pathophysiology]. Rev Esp Anestesiol Reanim. 2011;58(4):211-7. Spanish.

4. Silva LM, Kakuda CM, Abib AC, Fugiwara FY, Lima e Lara GF, Mazzotta RC, et al. Factors associated to postoperative pain in the post-anesthetic care unit in patients submitted to laparoscopic gastroplasty. Rev Dor. 2013;14(4):239-44.
5. Piccinini Filho L, Mathias LA, Malheiros CA, Gregori WM, Guaratini AA, Vieira JE. [Dexmedetomidine in morbid patients undergoing gastroplasty: cardiovascular stability and consumption of intravenous anesthetics. A retrospective study]. Rev Bras Anestesiol. 2006;56(2):109-18. Portuguese.

6. Lloret Linares C, Hajj A, Poitou C, Simoneau G, Clement K, Laplanche JL, et al. Pilot study examining the frequency of several gene polymorphisms involved in morphine pharmacodynamics and pharmacokinetics in a morbidly obese population. Obes Surg. 2011;21(8):1257-64.

7. Al-Alipour M, Mowafi HA, Ismail SA, Siddiqui AK, Al-Ghamdi AM, Shafi MA, et al. Effect of intra-articular dexmedetomidine on postoperative analgesia after arthroscopic knee surgery. Br J Anaesth. 2008;101(3):395-9.

8. Ramsay MA, Saha D, Hebeler RF. Tracheal resection in the morbidly obese patient: the role of dexmedetomidine. J Clin Anesth. 2006;18(6):452-4.

9. Feld JM, Hoffman WE, Stechert MM, Hoffman IW, Ananda RC. Fentanyl or dexmedetomidine combined with desflurane for bariatric surgery. J Clin Anesth. 2006;18(1):24-8.

10. Vaughns JD, Martin C, Nelson J, Nadler E, Quezado ZM. Dexmedetomidine as an adjuvant for perioperative pain management in adolescents undergoing bariatric surgery: an observational cohort study. J Pediatr Surg. 2017;52(11):1787-90.

11. Singh PM, Panwar R, Borle A, Mulier JP, Sinha A, Goudra B. Perioperative analgesic profile of dexmedetomidine infusions in morbidly obese undergoing bariatric surgery: a meta-analysis and trial sequential analysis. Surg Obes Relat Dis. 2017;13(8):1434-46.

12. Sudré EC, Salvador Mdo C, Bruno GE, Vasallo DV, Lauretti GR, Sudré Filho GN. [Remifentanil versus dexmedetomidine as coadjutants of standardized anesthetic technique in morbidly obese patients]. Rev Bras Anestesiol. 2004;54(2):178-89. Portuguese.

13. Segal IS, Vickery RG, Walton JK, Doze VA, Maze M. Dexmedetomidine diminishes halothane anesthetic requirements in rats through a postsynaptic alpha 2 adrenergic receptor. Anesthesiology. 1988;69(6):818-23.

14. Doze VA, Chen BX, Maze M. Dexmedetomidine produces a hypnotic-anesthetic action in rats via activation of central alpha-2 adrenoceptors. Anesthesiology. 1989;71(1):75-9.

15. Warlé MC, Dahan A. Does deep neuromuscular block affect pain after laparoscopic surgery? Eur J Anaesthesiol. 2017;34(1):23-4.

16. Tufanogullari B, White PF, Peixoto MP, Kianpour D, Lacour T, Griffin J, et al. Dexmedetomidine infusion during laparoscopic bariatric surgery: the effect on recovery outcome variables. Anesth Analg. 2008;106(6):1741-8. 